\title{
Endovascular Treatment of Active Splenic Bleeding After Colonoscopy: A Systematic Review of the Literature
}

\author{
Antonella Corcillo $\cdot$ Steve Aellen $\cdot$ Tobias Zingg • \\ Pierre Bize $\cdot$ Nicolas Demartines $\cdot$ Alban Denys
}

Received: 12 September 2012/ Accepted: 22 November 2012/Published online: 21 December 2012

(C) Springer Science+Business Media New York and the Cardiovascular and Interventional Radiological Society of Europe (CIRSE) 2012

\begin{abstract}
Purpose Colonoscopy is reported to be a safe procedure that is routinely performed for the diagnosis and treatment of colorectal diseases. Splenic rupture is considered to be a rare complication with high mortality and morbidity that requires immediate diagnosis and management. Nonoperative management (NOM), surgical treatment (ST), and, more recently, proximal splenic artery embolization (PSAE) have been proposed as treatment options. The goal of this study was to assess whether PSAE is safe even in high-grade ruptures.

Methods We report two rare cases of post colonoscopy splenic rupture. A systematic review of the literature from 2002 to 2010 (first reported case of PSAE) was performed and the three types of treatment compared.

Results All patients reviewed (77 of 77) presented with intraperitoneal hemorrhage due to isolated splenic trauma.
\end{abstract}

Antonella Corcillo and Steve Aellen contributed equally to this study.

A. Corcillo $(\square)$

Département de Médecine Interne, Centre Hospitalier

Universitaire Vaudois (CHUV), Lausanne, Switzerland

e-mail: antonella.corcillo@chuv.ch

S. Aellen · T. Zingg $\cdot$ N. Demartines

Service de Chirurgie Viscérale, Centre Hospitalier

Universitaire Vaudois (CHUV), Lausanne, Switzerland

e-mail: steve.aellen@hopitalvs.ch

\section{S. Aellen}

Service de Chirurgie Viscérale, Thoracique et Vasculaire, Centre Hospitalier du Centre du Valais (CHCVs), Av. du Grand-

Champsec 80, CP 736, 1951 Sion, Switzerland

P. Bize · A. Denys

Département de Radiologie Interventionnelle, Centre Hospitalier

Universitaire Vaudois (CHUV), Lausanne, Switzerland
Splenic rupture was high-grade in most patients when grading was possible. Six of 77 patients $(7.8 \%)$ were treated with PSAE, including the 2 cases reported herein. Fiftyseven patients (74\%) underwent ST. NOM was attempted first in 25 patients with a high failure rate (11 of 25 [44 \%]) and requiring a salvage procedure, such as PSAE or ST. Previous surgery (31 of 59 patients), adhesions (10 of 13), diagnostic colonoscopies (49 of 71), previous biopsies or polypectomies (31 of 57) and female sex (56 of 77) were identified as risk factors. In contrast, splenomegaly ( 0 of 77 patients), medications that increase the risk of bleeding (13 of 30) and difficult colonoscopies (16 of 51) were not identified as risk factors. PSAE was safe and effective even in elderly patients with comorbidities and those taking medications that increase the risk of bleeding, and the length of the hospital stay was similar to that after ST.

Conclusion We propose a treatment algorithm based on clinical and radiological criteria. Because of the high failure rate after NOM, PSAE should be the treatment of choice to manage grade I through IV splenic ruptures after colonoscopy in hemodynamically stabilized patients.

Keywords Splenic - Spleen - Colonoscopy - Rupture · Trauma $\cdot$ Embolization $\cdot$ Computed tomography-scan

\section{Introduction}

Colonoscopy is the investigation of choice for the diagnosis and treatment of colorectal tumors. An estimated 1.69 million screening colonoscopies are performed each year in the United States, [1] and >2,400 colonoscopies were performed in 2009 at our institution.

Although it is considered to be a safe procedure in experienced hands, the most frequent complications are 
intraluminal hemorrhage and colonic perforation (1-2 and 0.1-0.2\% incidence, respectively) [2]. The risk of complications increases if therapeutic procedures, such as polypectomy, are added [2, 3]. Although very rare, splenic rupture is known to be a serious complication with high morbidity and mortality rates. Its incidence, which is probably lower than that of perforation, is not known and is rarely reported: There have been $<80$ published cases in the literature worldwide since 2002. Even though presentation may be delayed, in most cases the patient presents within $24 \mathrm{~h}$ after the procedure and most require urgent management [2]. Rapid management, including fluid resuscitation, can prevent a fatal outcome. Successful treatment may also be obtained without surgery by a minimally invasive endovascular procedure that has been described for blunt splenic injury [4]. Because of the increase in the number of diagnostic and therapeutic colonoscopies, not only general practitioners, but also radiologists and emergency room specialists, will face increasing numbers of patients with this complication.

Thus, this review presents two consecutive cases of splenic rupture with active bleeding after colonoscopy who were both successfully treated with arterial embolization. A review of the literature describes the clinical circumstances, treatment modalities, and outcome of this rare condition. To our knowledge, this is the largest systematic review of the literature to date to describe this unusual complication and propose a treatment algorithm.

\section{Material and Methods}

Two cases of splenic bleeding after colonoscopy occurred at our institution and were treated with proximal splenic artery splenic embolization (PSAE). They were compared with similar cases in the literature. A PubMed search for English, French, German, and Italian articles was performed using the following key words: "splenic," "spleen," "colonoscopy," "rupture," "trauma," "embolization," and "computed tomography (CT) scan." Referenced articles were also considered. Because the first case to be treated by PSAE was reported in 2002, only relevant reports published between 2002 and 2010 were considered in the search flow chart (Fig. 1).

\section{Case No. 1}

A 66 year-old man underwent colonoscopy to investigate recurrent episodes of rectal bleeding. His medical history included hypertension, diabetes, hypercholesterolemia, severe vascular disease with hemorrhagic cerebrovascular events, multiple peripheral arterial revascularizations with iliac artery replacement, and pancreaticojejunostomy for chronic pancreatitis. Ongoing antiplatelet therapy was stopped for the procedure. Coagulation tests 3 days before colonoscopy were normal, and the hemoglobin concentration was $138 \mathrm{~g} / \mathrm{l}$. The patient was sedated with $5 \mathrm{mg}$ midazolam and $50 \mathrm{mg}$ pethidine. The colonoscopy was performed by a trainee and lasted $50 \mathrm{~min}$ with no reported difficulties. Cecal and transverse polypectomies were performed, leaving a sessile rectal polyp in situ because of its large implantation base of $5 \mathrm{~cm}$. Twelve hours after colonoscopy, the patient complained of sudden abdominal pain. On admission to the emergency room, his blood pressure was $84 / 55 \mathrm{~mm} \mathrm{Hg}$ and heart rate $100 \mathrm{bpm}$. Physical examination showed signs of peritoneal irritation. Hemodynamic stabilization was obtained with rapid perfusion of 1,000 ml saline solution. The initial hemoglobin concentration was $86 \mathrm{~g} / \mathrm{l}$ and the hematocrit $26 \%$, with normal blood coagulation tests. Abdominal CT scan showed hemoperitoneum in all four abdominal quadrants with grade IV splenic rupture based on the American Association for the Surgery of Trauma (AAST) classification [5] as well as active intraperitoneal bleeding (Fig. 2A, B). Active arterial splenic bleeding was not identified on selective angiography performed immediately after CT scan (Fig. 3A). Nevertheless, PSAE was performed with the patient under local anesthesia by placing a series of coils in the median part of the splenic trunk. This resulted in proximal splenic artery occlusion and interrupted distal flow causing immediate significant hemodynamic improvement (Fig. 3B, C).

The patient was monitored in the intensive care unit with ongoing fluid resuscitation. He received $2 \mathrm{U}$ packed red cells (PRCs) and $2 \mathrm{U}$ fresh frozen plasma (FFP). The clinical course was favorable, and the hemoglobin concentration remained stable. Follow-up CT scan showed regression of both subcapsular hematoma and free peritoneal fluid. Resection of the remaining tubulo-villous rectal adenoma by transanal endoscopic microsurgery was performed 11 days after embolization. However, the patient then developed a pneumococcal bacteremia, which was successfully treated with 10 days of antibiotherapy; he was finally discharged from the hospital 33 days after admission. Control CT scan performed 4 months after the procedure showed a well-vascularized spleen, and the platelet count was normal $\left(256 \times 10^{9}\right.$ thrombocytes/l).

Case No. 2

A 74-year-old woman was referred to our institution for a large cecal polyp that had been diagnosed in another hospital during a screening colonoscopy for constipation. Because of the size of the tumor, it could not be removed during the same procedure. Relevant medical history included beta blockers and acenocoumarol; the surgical history included 
Fig. 1 Flow chart of systematic search. PSAE proximal splenic artery embolization, NOM nonoperative management, $S T$ surgical treatment

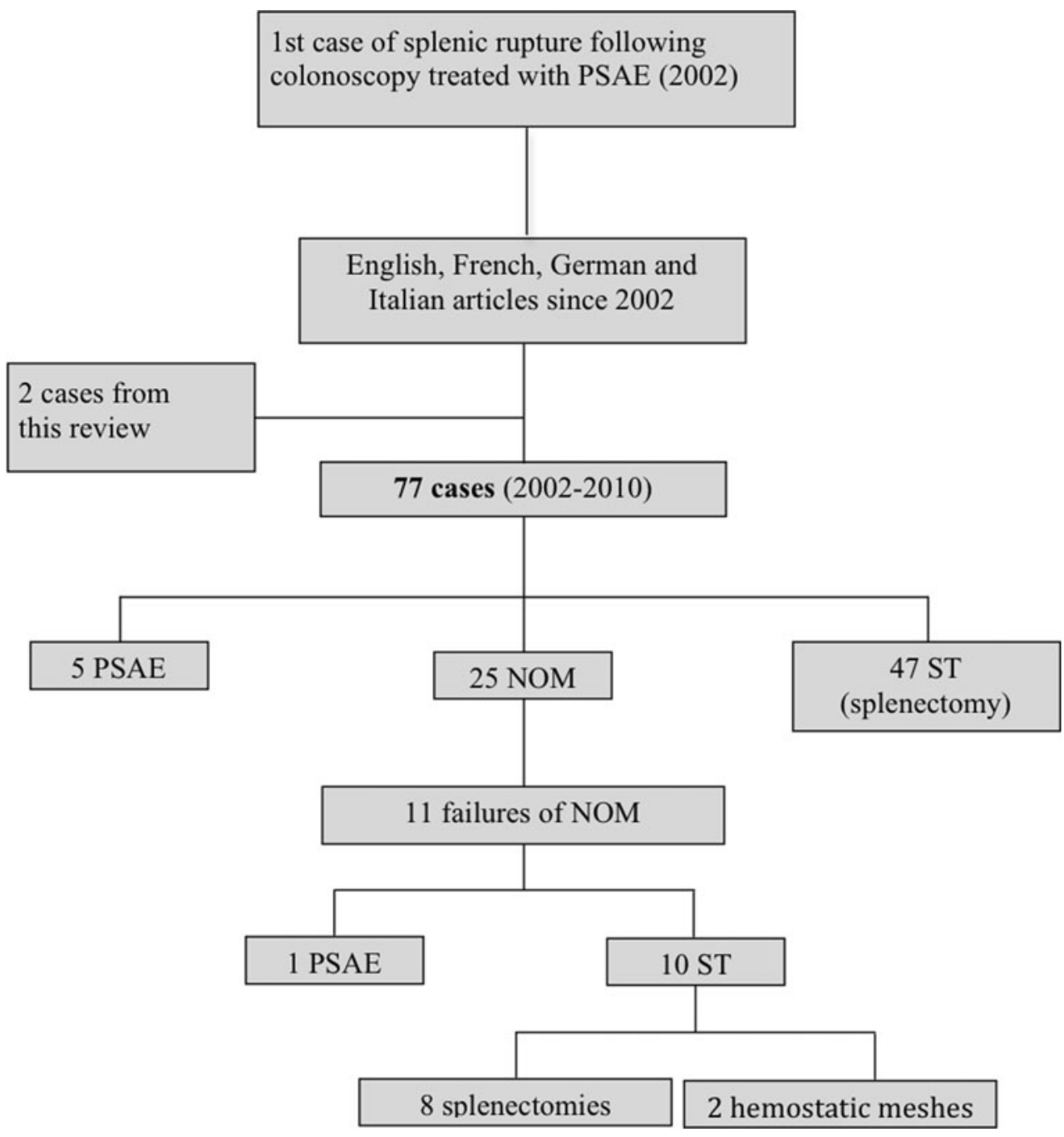

hysterectomy and appendectomy. Acenocoumarol was replaced by therapeutic low molecular-weight heparin in preparation for a second colonoscopy. This procedure was performed without patient sedation by a senior gastroenterologist consultant. The procedure lasted $20 \mathrm{~min}$. The cecal polyp could not be removed; however, rectal and transverse polypectomies were performed. One hour after discharge, the patient suddenly experienced progressive abdominal pain without rectal bleeding. The next day, she had syncope and was transferred to the hospital. Her blood pressure was $75 / 47 \mathrm{~mm} \mathrm{Hg}$ on admission, and the heart rate was $75 \mathrm{bpm}$. The physical examination showed signs of generalized peritoneal irritation. The patient responded well to resuscitation with $1,000 \mathrm{ml}$ saline solution and $500 \mathrm{ml}$ colloids and recovered a systolic pressure of $110 \mathrm{~mm} \mathrm{Hg}$. The hemoglobin concentration was $54 \mathrm{~g} / \mathrm{l}$; the hematocrit was $16 \%$; and blood coagulation tests were normal. Erect chest radiography showed no air under the diaphragmatic cupula. Abdominal CT scan showed hemoperitoneum in all four abdominal quadrants with an AAST grade IV splenic rupture [5]. PSAE was performed with coils with the patient under local anesthesia, and controlled the bleeding. The patient received 2 U PRC during the procedure. She was monitored in the intensive care unit and received an additional 4 U PRC and 2 U FFP. The patient remained stable throughout the rest of the hospital stay and did not require any additional transfusions. However, she developed pneumonia from an unknown bacteria 3 days after the procedure. Control CT scan performed 3 days after embolization showed a stable perisplenic hematoma and regression of hemoperitoneum. The patient was finally discharged from the hospital 11 days after the procedure. Ten months after embolization, the platelet count was within the normal range $\left(309 \times 10^{9}\right.$ thrombocytes/l). 

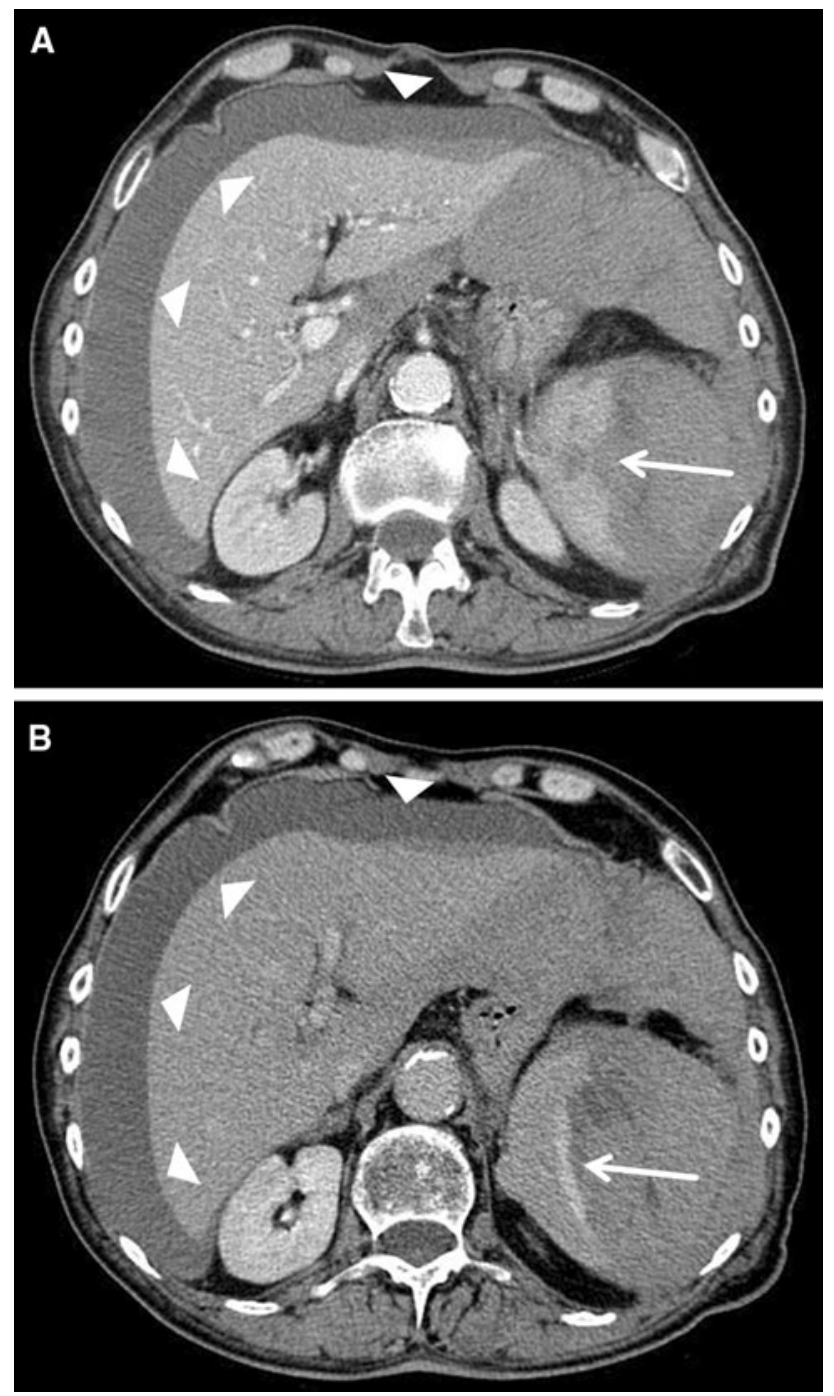

Fig. 2 Abdominal CT-scan showing a massive hemoperitoneum (arrowheads) due to complete splenic rupture (arrow). A Early (arterial) contrast enhanced acquisition. B Late contrast enhanced acquisition. Extravasation of contrast media throughout the splenic rupture (arrow)

\section{Results}

Seventy-five cases of splenic bleeding after colonoscopy have been reported in 51 publications [6-57]. Available data on patient characteristics, management, and outcome-including sex; age; colonoscopy type and any difficulties; sedation; additional procedures, such as biopsy; previous surgery; medications that increase the risk of bleeding; time until the first symptoms; hemodynamic instability; number of unites of PRC transfused; intraabdominal adhesions; length of hospital stay; and outcome-were collected and are listed in Tables 1 and 2. All of these factors were analyzed for the three different types of treatment.

\section{Patient Data}

The median age at colonoscopy was 65 years (range 29-85). The prevalence of iatrogenic splenic injury was higher in women than in men ( 56 of 77 vs. 21 of 77 patients). The six patients treated with PSAE were older than those treated with surgical treatment (ST) and nonoperative management (NOM) at a median age of 70.5 (range 60-81), 63.6 (range 38-82), and 60 (range 29-85) years respectively.

Previous abdominal surgery was reported in 4 of 6 patients who underwent PSAE. In the ST group, 20 of 45 (44.4\%) patients had undergone previous abdominal surgery, but there were no data on previous surgery in 12 of 57 patients. Intraabdominal adhesions were identified in 10 of 13 patients in the ST group, whereas no data were reported in 44 of 57 patients. There were no data on intra-abdominal adhesions or previous surgery in 6 of 14 patients in the NOM group. Seven of the 8 remaining patients who received NOM had undergone previous abdominal surgery. A pathological spleen was only found in 1 of 77 cases. This was due to primary amyloidosis and surgery was performed; however, there were no data on its size [23].

\section{Colonoscopy}

Diagnostic and screening colonoscopies were performed in 49 of $71(69.0 \%)$ and 22 of $71(31.0 \%)$ patients, respectively. Reports show that procedures were performed without any difficulty or external intraoperative manoeuvers in 35 of 51 patients $(68.6 \%)$. There was no data on sedation in most cases (60 of 77). Biopsy or polypectomy procedures were performed in 31 of 57 patients $(54.4 \%)$, whereas no data were reported in the remaining 20 of 77 . Biopsy or polypectomy procedures were performed in several sites in the colon but predominantly in the rectum and descending colon (15 patients), the transverse colon (5 patients), and the ascending colon and cecum (10 patients). This information was only reported in 23 of 77 patients.

Anticoagulants, Antiplatelet Therapy, or Medication Increasing the Risk of Bleeding

Information on medications that increase the risk of bleeding, such as anticoagulants, antiplatelets, nonsteroidal anti-inflammatory drugs (NSAIDs), and acetylsalicylic acid (ASA), was available in 30 of 77 patients (39\%) (4 of 6 in the PSAE, 22 of 57 in the ST, and 4 of 14 in the NOM groups). These treatments were being taken by 13 of 30 ( $43 \%$ ) of these patients ( 3 of 4 in the PSAE, 8 of 22 in the ST, and 2 of 4 in the NOM groups).

\section{Clinical Presentation at Hospital}

Seventy-four patients presented with signs and symptoms of splenic rupture within a median of $12 \mathrm{~h}$ after the 

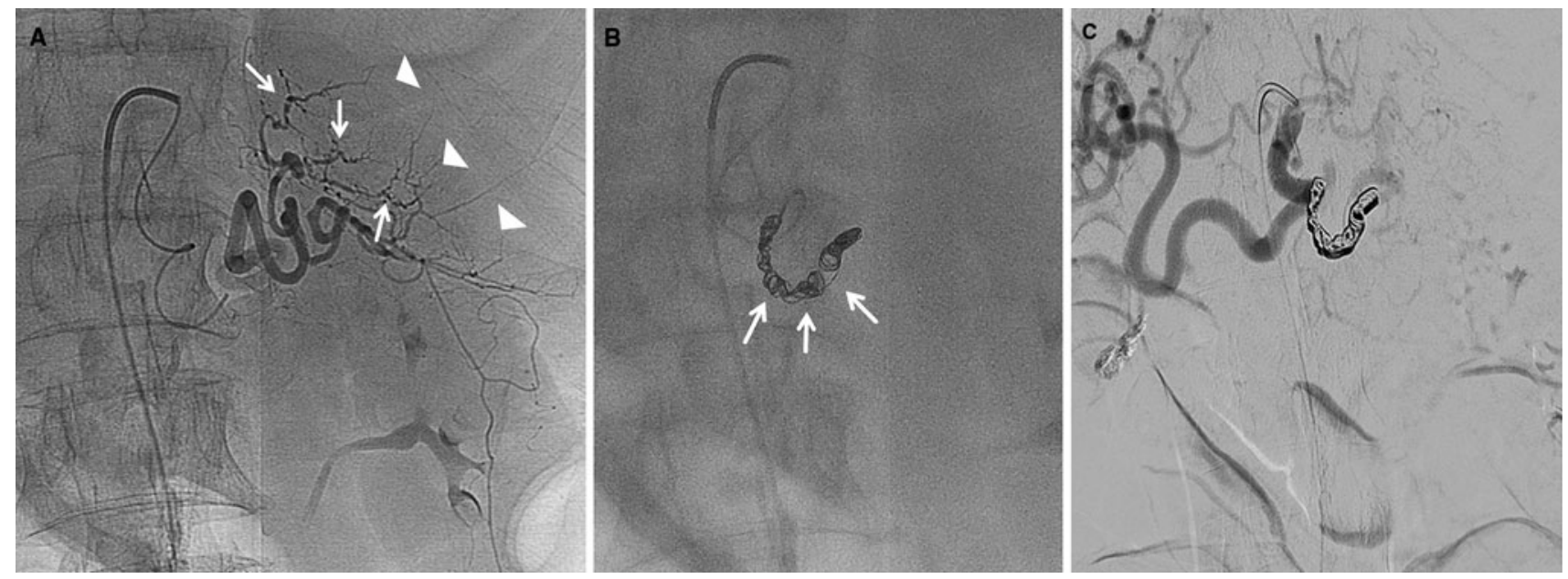

Fig. 3 Splenic arteriography. A The splenic vessels are grossly displaced by the perisplenic hematoma (arrowheads). The diameter is also irregular with active vascular spasm (arrow), but no obvious active bleeding. B Embolization of the proximal splenic artery by

procedure (range 0-288). This information was not available for 3 of 77 patients. The onset of symptoms was delayed by several days in 9 of 74 cases. At admission, 47 of 69 patients $(68.1 \%)$ were found to be hemodynamically unstable. An emergency procedure (1 SAE and $10 \mathrm{ST}$ ) was required in 11 patients who became unstable after admission.

\section{Number of Units of PRCs}

The number of units of PRCs transfused did not depend on the type of treatment. Transfusions with a median of 4 U PRC (range 1-14) were reported in 26 of 30 patients, whereas this information was not provided for 47 of 77 patients. On arrival in the emergency room, the decrease in hemoglobin levels was 52 and $54 \mathrm{~g} / 1$, respectively, in 2 PSAE patients and a median of $52 \mathrm{~g} / \mathrm{l}$ (range 18-85) in $13 \mathrm{ST}$ patients but only a median of $20 \mathrm{~g} / \mathrm{l}$ in $5 \mathrm{NOM}$ patients (range 11-54). Moreover, embolization was effective in 3 PSAE patients who were taking anticoagulation or antiplatelet therapy with 1,4 , and 5 U PRC transfused, respectively.

\section{Management}

Percutaneous PSAE was performed in 6 of 77 patients $(7.8 \%)$. Laparotomy and splenectomy were performed in 57 of 77 cases $(74 \%)$. Conservative treatment (NOM), which included bed rest, transfusions, and pain control, was performed in 25 of 77 patients (32.5\%). It was successful in 14 of 25 patients (56\%), but rebleeding occurred in 11 of 25 patients (44\%). Surgery-including 8 splenectomies, 2 hemostatic meshes, and 1 PSAE - was performed in 10 cases due to hemodynamic instability or secondary rupture. Splenic lesions, except for blunt splenic trauma, were not coils (arrows) placed in the median part of the splenic trunk. C The blood flow in the distal splenic artery has been interrupted by embolization

routinely graded according to AAST classification, making determination of splenic lesions difficult [5].

\section{Outcome}

Patients stayed in the hospital for a median of 10 days (range 3-12) in the PSAE group (5 of 6 patients), 9 days (range $3-22$ ) in the ST group (29 of 57 patients), and 3 days (range $0-10$ ) in the NOM group (11 of 14 patients). Pulmonary complications developed in 3 of 6 patients in the PSAE group. One patient died from respiratory insufficiency due worsening of chronic obstructive airway disease [9]. In the ST group, 13 of 57 (22.8\%) patients developed complicaileus. One patient with pulmonary silicosis developed postoperative respiratory insufficiency and died 16 days after splenectomy [30]. Another patient underwent 3 additional operations: one for postoperative bleeding, one for intestinal obstruction due to adhesions 1 month later, and finally a third laparotomy for intestinal perforation, after which the patient died [30]. Wound infections, myocardial infarcts, rebleeding, secondary infection of the splenic hematoma, and pancreatic duct injury were also reported as complications. No complications were observed in the 14 of 25 patients who were successfully treated with NOM.

\section{Discussion}

The two cases reported here had severe bleeding from splenic rupture after colonoscopy and were treated successfully by PSAE. Although very rare, post colonoscopy intraperitoneal hemorrhage is usually reported to be due to splenic injury. Other sources of hemoperitoneum after colonoscopy are tions, mostly respiratory insufficiency and postoperative 


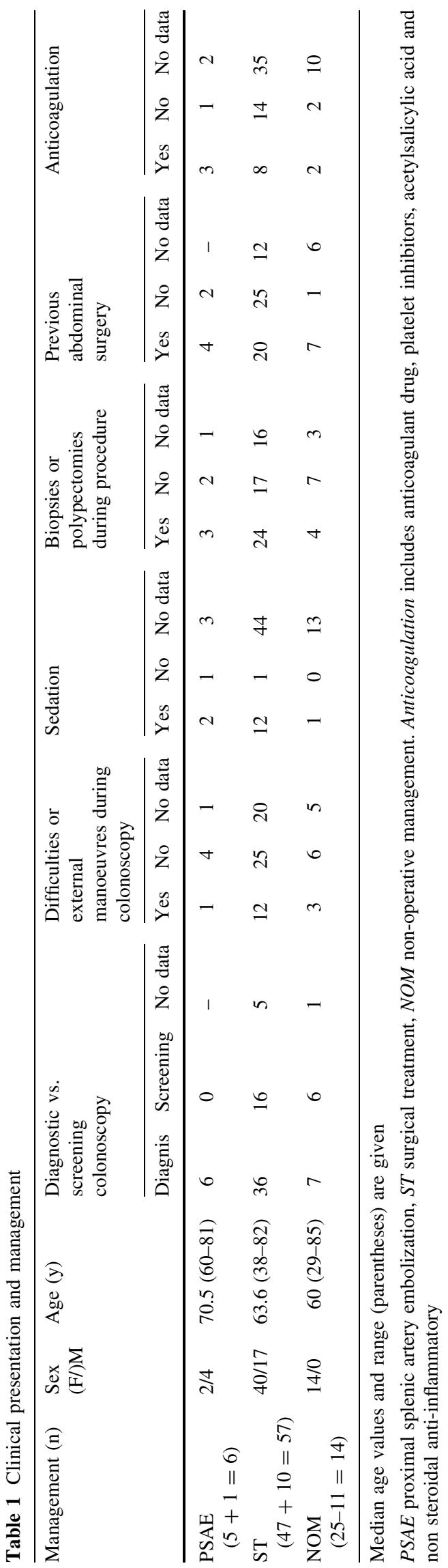

extremely unusual and include a torn mesenteric vessel, a ruptured appendix epiploica, and bleeding from a necrotic intestinal leiomyosarcoma [58].

Hypothetic mechanisms of splenic injury are direct trauma by the endoscope when it is positioned in the splenic flexure or excessive traction on the splenocolic ligament when pushing the endoscope into the transverse colon. The result is avulsion of the splenic capsule and parenchymal disruption of various grades. Predisposing factors, such as previous intra-abdominal surgery causing adhesions, splenomegaly, medications increasing the risk of bleeding, difficult colonoscopy, and therapeutic colonoscopy, have been suggested $[7,36]$. The present review confirms that previous surgery and the presence of adhesions are risk factors of splenic injury: Adhesions have been reported in 10 of 13 patients who underwent surgery, whereas 31 of 59 had undergone previous surgery. Diagnostic colonoscopies (49 of 71 patients), biopsies, or polypectomies (31 of 57) and female sex (56 of 77) were other identified risk factors. Conversely, splenomegaly ( 0 of 77 patients with 1 case of amyloidosis without splenomegaly [23]), medications that increase the risk of bleeding (13 of 30 cases), and difficult colonoscopies (16 of 51 cases) were not identified as risk factors. Although recent data have suggested that inflammatory bowel disease, pancreatitis, rapid completion time, a history of chronic smoking, propofol sedation, and inadequate colon wash-out were associated with a greater risk of splenic rupture [36, 59], there were no data on these issues in this review.

Splenic bleeding after colonoscopy is life-threatening. This review showed that 47 of $69(68.1 \%)$ patients presented with hemodynamic shock at diagnosis. Small splenic lesions might be misdiagnosed in patients with slight symptoms who do not consult a physician or in whom further investigations are not performed. Thus, the most severe cases of splenic rupture are seen in the hospital and require emergency management. Most patients described in this article presented with severe bleeding corresponding to high grades of splenic trauma (III to IV) according to the AAST classification [5] with 26 of 30 patients requiring transfusion.

Because this condition can be fatal, active management should be started with fluid resuscitation, followed-up by abdominal CT-scan for diagnosis, as long as the patient remains hemodynamically stable. A flow chart for management is shown in Fig. 4.

Management of this isolated organ trauma should follow AAST recommendations for management of blunt splenic trauma. Thus, the protocol for investigating patients with severe acute abdominal pain after colonoscopy, especially if it is associated with hemodynamic shock, should be FAST (focused assessment with sonography for trauma) and contrast-enhanced abdominal CT scan, both of which 
Table 2 Clinical presentation and management

\begin{tabular}{|c|c|c|c|c|c|c|c|c|c|c|c|c|c|c|c|c|c|}
\hline \multirow[t]{2}{*}{ Management (n) } & \multicolumn{2}{|c|}{$\begin{array}{l}\text { Time (h) until } \\
\text { onset of } \\
\text { symptoms } \\
\text { from } \\
\text { colonoscopy } \\
\text { (median, } \\
\text { range) }\end{array}$} & \multicolumn{2}{|l|}{$\begin{array}{l}\text { Decrease in } \\
\text { hemoglobin } \\
\text { rate }(\mathrm{g} / \mathrm{l})\end{array}$} & \multicolumn{3}{|c|}{$\begin{array}{l}\text { Presence of } \\
\text { hemodynamic } \\
\text { instability (systolic } \\
\text { BP }<90 \mathrm{~mm} \mathrm{Hg} \text {, } \\
\text { tachycardia, } \\
\text { tachypnea) }\end{array}$} & \multicolumn{2}{|c|}{$\begin{array}{l}\text { Number of U } \\
\text { of PRC } \\
\text { transfusions }\end{array}$} & \multicolumn{3}{|c|}{$\begin{array}{l}\text { Presence of } \\
\text { intra-abdominal } \\
\text { adhesions }\end{array}$} & \multicolumn{2}{|c|}{$\begin{array}{l}\text { Length of } \\
\text { hospital stay (d) }\end{array}$} & \multicolumn{3}{|c|}{$\begin{array}{l}\text { Postoperative } \\
\text { complications } \\
\text { (medical and } \\
\text { surgical) }\end{array}$} \\
\hline & No data & & No data & & Yes & No & $\begin{array}{l}\text { No } \\
\text { data }\end{array}$ & & $\begin{array}{l}\text { No } \\
\text { data }\end{array}$ & Yes & No & $\begin{array}{l}\text { No } \\
\text { data }\end{array}$ & & $\begin{array}{l}\text { No } \\
\text { data }\end{array}$ & Yes & No & $\begin{array}{l}\text { No } \\
\text { data }\end{array}$ \\
\hline $\begin{array}{l}\text { PSAE } \\
\qquad(5+1=6)\end{array}$ & $36(1-120)$ & 0 & $53(52-54)$ & 4 & 5 & 0 & 1 & $4(1-5)$ & 1 & NA & & & $10(3-12)$ & 1 & 3 & 2 & 1 \\
\hline $\begin{array}{l}\text { ST } \\
\quad(47+10=57)\end{array}$ & $12(0-288)$ & 2 & $\begin{array}{l}52(18-85) \\
\text { no decrease : } \\
1\end{array}$ & 43 & 42 & 12 & 3 & $5(2-14)$ & 37 & 10 & 3 & 44 & $9(3-22)$ & 28 & 13 & 29 & 15 \\
\hline $\begin{array}{l}\text { NOM } \\
\quad(25-11=14)\end{array}$ & $6(3-96)$ & 1 & $20(11-54)$ & 9 & 0 & 10 & 4 & $4(4-6)$ & 9 & NA & & & $3(0-10)$ & 3 & 0 & 12 & 2 \\
\hline
\end{tabular}

Median age values and range (parentheses) are given

$P S A E$ proximal splenic artery embolization, $S T$ surgical treatment, NOM non-operative management, $P R C$ packed red cells, $N D$ no data available, $N A$ not applicable

Fig. 4 Management of splenic rupture following colonoscopy, PSAE proximal splenic artery embolization, NOM non operative management, $S T$ surgical treatment, $I R$ interventional radiologist, $A A S T$ American Association for the Surgery of Trauma, FAST focused assessment with sonography for trauma

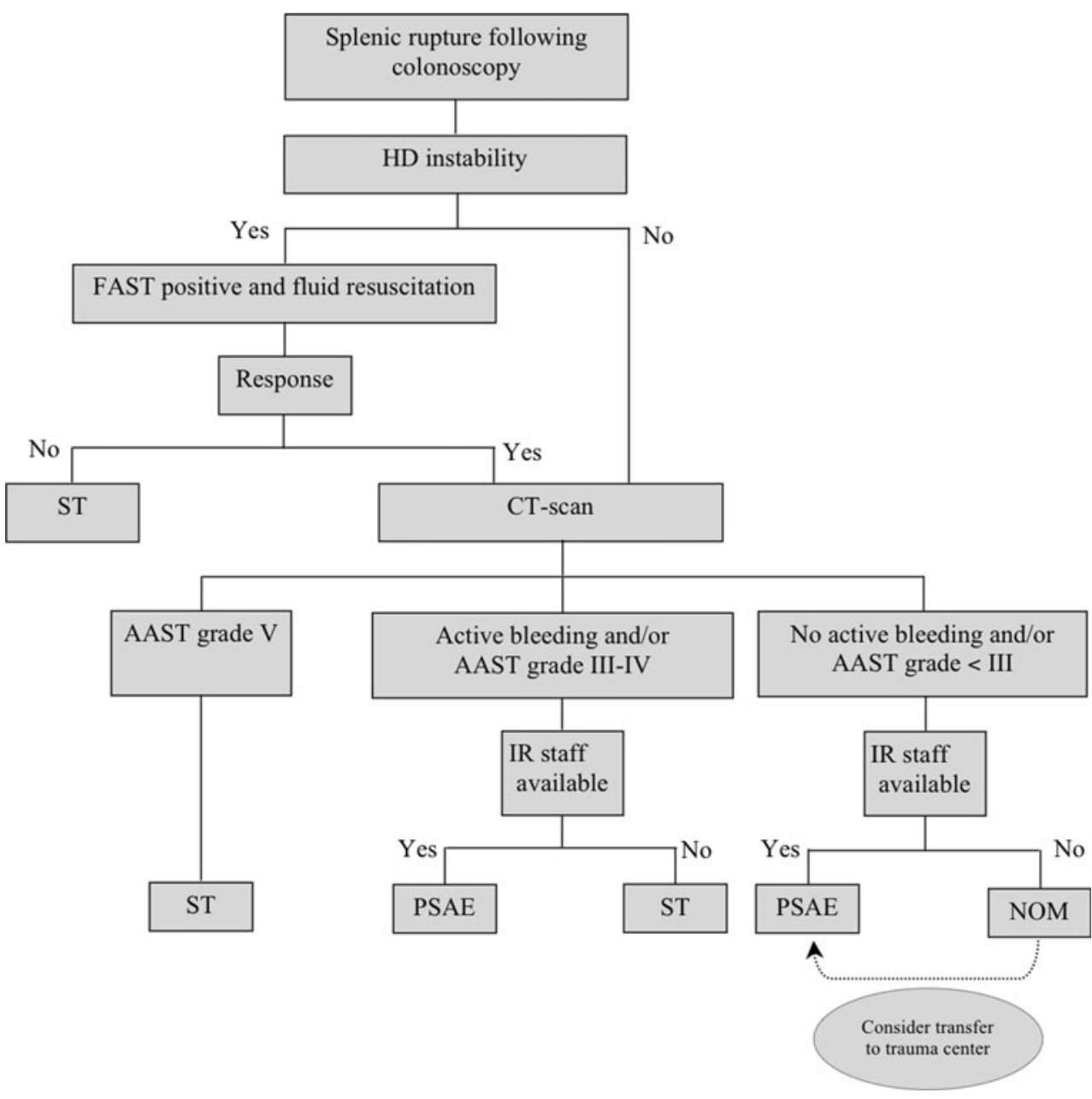

are the standard diagnostic tools used in the setting of blunt abdominal trauma [5]. Sensitivity of FAST for intraabdominal fluid detection in hemodynamically unstable patients is considered to be between 63 and $96 \%$ [60].
A positive FAST is usually a sufficient indication for exploratory laparotomy. Abdominal CT scan is the imaging modality of choice in hemodynamically stable patients or in those with a positive response to fluid resuscitation. The 
sensitivity and specificity of CT scan for the detection of splenic injuries is as high as $98 \%$ [60]. In the two reported cases, intra-abdominal hemorrhage secondary to splenic rupture was confirmed by contrast-enhanced CT scan. The injury should be radiologically graded in reference to the AAST classification for blunt splenic trauma [5], and although there is no definite consensus, grades of up to III and IV should usually be treated with PSAE or ST, whereas grades I and II should be treated with NOM [61]. Recent publication suggest that PSAE could be more beneficial in patients with low-grade splenic injury [62]. Grade V injuries require ST. The use of NOM has increased in the past decade, and an estimated $85 \%$ patients now undergo this treatment [63]. Nevertheless, in case of post colonoscopy trauma, NOM seems to fail more frequently than for blunt trauma with 11 of 25 patients (44\%) requiring a salvage procedure (PSAE or ST) compared with 16 of 159 of patients (10\%), respectively [64]. In addition, PSAE is increasingly performed in combination with NOM, thus decreasing the failure rate from $12-13$ to $2-3 \%$ [63, 65, 66]. PSAE appears to be safe and effective even in elderly patients with comorbidities and those taking medication that increase the risk of bleeding. The 2 cases reported in this review corresponded to grade IV injuries, suggesting that manipulation of the colonoscope on the splenic flexure may be as severe or worse than blunt external trauma. PSAE provided effective long-term haemostasis in both cases. Due to high failure rate of NOM in this specific condition, a more extensive use of PSAE, compared with usual recommendation in the general polytrauma population, can be proposed [61].

Obviously, risk factors, such as hemodynamic instability or not responding to fluid resuscitation, advanced age with the presence of severe associated diseases, or medications that increase the risk of bleeding, must be taken into consideration. Nevertheless considering the high failure rate of NOM alone, a conservative therapeutic approach combined with interventional radiology should be an alternative to surgery.

Interestingly, PSAE did not decrease the hospital stay compared with ST. Some surgeons may feel safer and more comfortable with performing a splenectomy than embolization due to a perceived risk of secondary rupture of the spleen. Death occurred in 3 of 77 patients (3.9\%) (2 in the ST group and 1 in the PSAE group). Considering that only isolated splenic traumas were included, this rate is significantly lower than that $(8 \%)$ after splenectomy for external blunt trauma [4]. Our two patients developed pneumonia during hospitalization. Although splenic function does not seem to be impaired after PSAE [4], the blood culture of the first patient was positive for Streptococcus pneumoniae 10 days after the procedure. Platelet counts in both patients remained normal a few months after the procedure. PSAE is a well-tolerated technique that presents no major long- term influence on splenic function in patients with sufficient immunity against Haemophilus influenza $B$ and pneumococcus. Although vaccination against these bacteria has been suggested, no consensus exists for cases of splenic artery embolization [4].

To our knowledge, only four previous cases of endovascular treatment of splenic rupture after colonoscopy have been reported [6-9]. Our analysis suggests that this complication is underestimated and underreported, with $<80$ cases having been reported worldwide between 2002 and 2010.

In conclusion, although colonoscopy performed by an experienced operator is a safe procedure, it is by no means harmless. Splenic rupture, such as bowel perforation and intraluminal bleeding, should be considered as a potential cause of abdominal pain in the presence of hemodynamic shock after colonoscopy. Because of the extended indications for colonoscopy, clinicians should be more aware of this complication. The identified risk factors are adhesions, female sex, diagnostic colonoscopy with biopsy, and medications that increase the risk of bleeding. Splenic lesions are high-grade, and conservative management is associated with a high failure rate. Thus, active management with a less invasive procedure, such as PSAE, should always be considered in a patient with splenic rupture after colonoscopy. PSAE for isolated splenic trauma is safe and effective and should be considered the method of choice in the above-mentioned specific situations according to the flow chart guidelines.

Conflict of interest All the authors declare that they have no conflict of interest.

\section{References}

1. Vijan S, Inadomi J, Hayward RA et al (2004) Projections of demand and capacity for colonoscopy related to increasing rates of colorectal cancer screening in the United States. Aliment Pharmacol Ther 20:507-515

2. Macrae FA, Tan KG, Williams CB (1983) Towards safer colonoscopy: a report on the complications of 5000 diagnostic or therapeutic colonoscopies. Gut 24:376-383

3. Schwesinger WH, Levine BA, Ramos R (1979) Complications in colonoscopy. Surg Gynecol Obstet 148:270-281

4. Bessoud B, Duchosal MA, Siegrist CA et al (2007) Proximal splenic artery embolization for blunt splenic injury: clinical, immunologic, and ultrasound-doppler follow-up. J Trauma 62:1481-1486

5. Moore EE, Cogbill TH, Jurkovich GJ et al (1995) Organ injury scaling: spleen and liver (1994 revision). J Trauma 38:323-324

6. Stein DF, Myaing M, Guillaume C (2002) Splenic rupture after colonoscopy treated by splenic artery embolization. Gastrointest Endosc 55:946-948

7. Holubar S, Dwivedi A, Eisdorfer J et al (2007) Splenic rupture: an unusual complication of colonoscopy. Am Surg 73:393-396

8. Parker WT, Edwards MA, Bittner JG 4th et al (2008) Splenic hemorrhage: an unexpected complication after colonoscopy. Am Surg 74:450-452 
9. de Vries J, Ronnen HR, Oomen AP et al (2009) Splenic rupture following colonoscopy, a rare complication. Neth J Med 67:203-230

10. Rinzivillo C, Minutolo V, Gagliano G et al (2003) Splenic trauma following colonoscopy. G Chir 24:309-311

11. Al Alawi I, Gourlay R (2004) Rare complication of colonoscopy. ANZ J Surg 74:605-606

12. Goitein D, Goitein O, Pikarski A (2004) Splenic rupture after colonoscopy. Isr Med Assoc J 6:61-62

13. Jaboury I (2004) Splenic rupture after colonoscopy. Intern Med J $34: 652-653$

14. Janes SE, Cowan IA, Dijkstra B (2005) A life threatening complication after colonoscopy. BMJ 330(7496):889-890

15. Naini MA, Masoompour SM (2005) Splenic rupture as a complication of colonoscopy. Indian J Gastroenterol 24:264-265

16. Shah PR, Raman S, Haray PN (2005) Splenic rupture following colonoscopy: rare in the UK? Surgeon 3:293-295

17. Weisgerber K, Lutz MP (2005) Splenic rupture after colonoscopy. Clin Gastroenterol Hepatol 3:A24

18. Johnson C, Mader M, Edwards DM et al (2006) Splenic rupture following colonoscopy: two cases with CT findings. Emerg Radiol 13:47-49

19. Luebke T, Baldus SE, Holscher AH et al (2006) Splenic rupture: an unusual complication of colonoscopy: case report and review of the literature. Surg Laparosc Endosc Percutan Tech 16:351354

20. Shatz DV, Rivas LA, Doherty JC (2006) Management options of colonoscopic splenic injury. JSLS 10:239-243

21. Volchok J, Cohn M (2006) Rare complications following colonoscopy: case reports of splenic rupture and appendicitis. JSLS 10:114-116

22. Zenooz NA, Win T (2006) Splenic rupture after diagnostic colonoscopy: a case report. Emerg Radiol 12:272-273

23. Zerbi S, Crippa S, Di Bella C et al (2006) Splenic rupture following colonoscopy in a hemodialysis patient. Int $\mathrm{J}$ Artif Organs 29:335-336

24. Di Lecce F, Viganò P, Pilati S et al (2007) Splenic rupture after colonoscopy. a case report and review of the literature. Chir Ital 59:755-757

25. Lalor PF, Mann BD (2007) Splenic rupture after colonoscopy. JSLS 11:151-156

26. Pfefferkorn U, Hamel CT, Viehl CT et al (2007) Haemorrhagic shock caused by splenic rupture following routine colonoscopy. Int J Colorectal Dis 22:559-560

27. Cappellani A, Di Vita M, Zanghì A et al (2008) Splenic rupture after colonoscopy: report of a case and review of literature. World J Emerg Surg 3:8

28. Famularo G, Minisola G, De Simone C (2008) Rupture of the spleen after colonoscopy: a life-threatening complication. Am J Emerg Med 26:834

29. Guerra JF, San Francisco I, Pimentel F et al (2008) Splenic rupture following colonoscopy. World J Gastroenterol 14:6410-6412

30. Petersen CR, Adamsen S, Gocht-Jensen P et al (2008) Splenic injury after colonoscopy. Endoscopy 40:76-79

31. Pichon N, Mathonnet M, Verdière F et al (2008) Splenic trauma: an unusual complication of colonoscopy with polypectomy. Gastroenterol Clin Biol 32:123-127

32. Schilling D, Kirr H, Mairhofer C et al (2008) Splenic rupture after colonoscopy. Dtsch Med Wochenschr 133:833-835

33. Kamath AS, Iqbal CW, Sarr MG et al (2009) Colonoscopic splenic injuries: incidence and management. J Gastrointest Surg 13:2136-2140

34. Kiosoglous AJ, Varghese R, Memon MA (2009) Splenic rupture after colonoscopy: a case report. Surg Laparosc Endosc Percutan Tech 19:e104-e105

35. Lewis SR, Ohio D, Rowley G (2009) Splenic injury as a rare complication of colonoscopy. Emerg Med J 26:147
36. Sarhan M, Ramcharan A, Ponnapalli S (2009) Splenic injury after elective colonoscopy. JSLS 13:616-619

37. Patselas TN, Gallagher EG (2009) Splenic rupture: an uncommon complication after colonoscopy. Am Surg 75:260-261

38. Skipworth JR, Raptis DA, Rawal JS et al (2009) Splenic injury following colonoscopy-an underdiagnosed, but soon to increase, phenomenon? Ann R Coll Surg Engl 91:W6-W11

39. Younes NA, Al-Ardah MI, Daradkeh SS (2009) Rupture of spleen post colonoscopy. Saudi Med J 30:1095-1097

40. DuCoin C, Acholonu E, Ukleja A et al (2010) Splenic rupture after screening colonoscopy: case report and literature review. Surg Laparosc Endosc Percutan Tech 20:e31-e33

41. Meier RP, Toso C, Volonte F et al (2011) Splenic rupture after colonoscopy. Am J Emerg Med 29:241.e1-241.e2

42. Michetti CP, Smeltzer E, Fakhry SM (2010) Splenic injury due to colonoscopy: Analysis of the world literature, a new case report, and recommendations for management. Am Surg 76:1198-1204

43. Murariu D, Takekawa S, Furumoto N (2010) Splenic rupture: A case of massive hemoperitoneum following therapeutic colonoscopy. Hawaii Med J 69:140-141

44. Rasul T, Leung E, McArdle K et al (2010) Splenic rupture following routine colonoscopy. Dig Endosc 22:351-353

45. Pothula A, Lampert J, Mazeh H et al (2010) Splenic rupture as a complication of colonoscopy: report of a case. Surg Today 40:68-71

46. Stauch P, Dietrich P, Bernhard M et al (2010) Spleen ruptures after screening colonoscopy. Chirurg 81:746-749

47. Theodoropoulos J, Krecioch P, Myrick S et al (2010) Delayed presentation of a splenic injury after colonoscopy: a diagnostic challenge. Int J Colorectal Dis 25:1033-1034

48. Weidman MW, Kater F, Bohme B (2010) Splenic rupture following endoscopic polypectomy. Z Gastroenterol 48:476-478

49. Hamzi L, Soyer P, Boudiaf M et al (2003) Splenic rupture following colonoscopy: report of an unusual case in the absence of underlying splenic disease. J Radiol 84:320-322

50. Boghossian T, Carter JW (2004) Early presentation of splenic injury after colonoscopy. Can J Surg 47:148

51. Holzer K, Thalhammer A, Bechstein WO (2004) Splenic trauma-a rare complication during colonoscopy. Z Gastroenterol 42:509-512

52. Leaks BJ (2004) Splenic hematoma as a complication of colonoscopy. J Am Geriatr Soc 52:320-321

53. Prowda JC, Trevisan SG, Lev-Toaff AS (2005) Splenic injury after colonoscopy: conservative management using CT. AJR Am J Roentgenol 185:708-710

54. Tsoraides SS, Gupta SK, Estes NC (2007) Splenic rupture after colonoscopy: case report and literature review. J Trauma 62:255-257

55. Duarte CG (2008) Splenic rupture after colonoscopy. Am J Emerg Med 26:117

56. Saad A, Rex DK (2008) Colonoscopy-induced splenic injury: report of 3 cases and literature review. Dig Dis Sci 53:892-898

57. Ranganath R, Selinger S (2009) An uncommon complication of a common procedure. Postgrad Med J 85(1002):224

58. Tagg W, Woods S, Razdan R et al (2008) Hemoperitoneum after colonoscopy. Endoscopy 40(Suppl 2):E136-E137

59. Rao KV, Beri GD, Sterling MJ et al (2009) Splenic injury as a complication of colonoscopy: a cases series. Am J Gastroenterol 104:1604-1605

60. Poletti PA, Wintermark M, Schnyder P et al (2002) Traumatic injuries: role of imaging in the management of the polytrauma victim (conservative expectation). Eur Radiol 12:969-978

61. Van der Vlies CH, van Delden OM, Punt BJ et al (2010) Literature review of the role of ultrasound, computed tomography and transcatheter arterial embolization for the treatment of traumatic splenic injuries. Cardiovasc Interment Radiol 33(6):1079-1087

62. Van der Vlies CH, Hoekstra J, Ponsen KJ et al (2012) Impact of splenic artery embolization on the success rate of nonoperative 
management for blunt splenic injury. Cardiovasc Intervent Radiol 35(1):76-81

63. Moore FA, Davies JW, Moore EE et al (2008) Western Trauma Association (WTA) critical decision in trauma: management of adult blunt splenic trauma. J Trauma 65:1007-1011

64. Renzulli P, Hostettler A, Schoepfer AM et al (2009) Systematic review of atraumatic splenic rupture. Br J Surg 96:1114-1121
65. Bessoud B, Denys A (2004) Main splenic artery embolisation using coils in blunt splenic injuries: effects on the intrasplenic blood pressure. Eur Radiol 14:1718-1719

66. Haan JM, Biffl W, Knudson MM et al (2004) Splenic embolization revisited: a multicenter review. J Trauma 56:542-547 